\title{
Penerapan Metode Rapid Application Development pada Sistem Informasi Persediaan Barang berbasis Web
}

\author{
Biktra Rudianto $^{1}$, Yuni Eka Achyani ${ }^{2}$ \\ Sekolah Tinggi Manajemen Informatika dan Komputer Nusa Mandiri ${ }^{1,2}$ \\ Biktra.brd@nusamandiri.ac.id¹, yuni.yea@nusamandiri.ac.id ${ }^{2}$
}

\begin{abstract}
Abstrak - Pada saat ini teknologi informasi berkembang sangat pesat dan menuntut para pelaku usaha untuk bisa mengikuti perkembangan dan kemajuan zaman, khususnya dalam dunia teknologi dan informasi. Persediaan barang dagang merupakan aset perusahaan yang menjadi salah satu aset yang termasuk aktiva lancar. Persediaan barang dagang adalah aset perusahaan yang dibeli dan disimpan untuk dijuat kembali dan mendapatkan keuntungan. Pencataan persediaan barang dagang yang masih bersifat manual seperti pendataan barang masuk, permintaan barang, pengiriman barang, pengembalian barang sampai dengan pembuatan laporan tentu akan mengakibatkan penumpukan nota permintaan barang. Sulitnya pendataan permintaan barang dari cabang untuk melakukan pengiriman barang, kesalahan barang yang diminta dan yang dikirim, lamanya pencatatan pengembalian barang, kesalahan dalam perhitungan stok barang serta sulitnya mendapatkan laporan pada saat dibutuhkan juga merupakan salah satu kendala dalam proses persediaan barang dagang. oleh karena itu dibutuhkan suatu sistem informasi persediaan barang berbasis web agar dapat mempermudah pengguna dalam mengelola proses persediaan barang dagangnya, sehingga dapat mempermudah dalam proses pencatatan, penyimpanan, pencarian serta pembuatan laporan. Dalam perancangan sistem informasi persediaan barang berbasis web ini, penulis menggunakan metode Rapid Application Development (RAD). Sistem Informasi ini merupakan solusi terbaik untuk pemecahan masalah dalam pengelolaan persediaan barang. Dengan penggunaan teknologi data komputer yang dikelola menjadi lebih cepat, mengurangi ketidakefisienan waktu dan mengurangi terjadinya kesalahan dalam mengolah data.
\end{abstract}

Kata Kunci : Persediaan, Sistem Informasi, Web, RAD

Abstract - At this time information technology is developing very rapidly and requires business actors to be able to follow the developments and advances of the times, especially in the world of technology and information. Inventory of merchandise is a company asset that is one of the assets included in current assets. Merchandise inventories are company assets that are purchased and stored to be resold and make a profit. Recording of merchandise inventory that is still manual, such as data collection of incoming goods, demand for goods, delivery of goods, returns of goods to the preparation of reports will certainly result in the accumulation of goods request notes. The difficulty of data collection of requests for goods from branches to deliver goods, errors in goods requested and sent, the length of time to record the return of goods, errors in calculating the stock of goods and difficulty in obtaining reports when needed are also one of the obstacles in the process of merchandise inventory. Therefore, a web-based inventory information system is needed in order to make it easier for users to manage the inventory process of their merchandise, so that it can simplify the process of recording, storing, searching and making reports. In designing a web-based inventory information system, the author uses the Rapid Application Development (RAD) method. This information system is the best solution for solving problems in managing inventory. With the use of computer data technology, managed data becomes faster, reduces time inefficiency and reduces the occurrence of errors in processing data.

Keywords: Inventory, Information Systems, Web, RAD

\section{PENDAHULUAN}

Persediaan barang merupakan bagian yang sangat penting bagi suatu perusahaan, karena itu sudah mulai banyak pengusaha atau pelaku dagang yang menggunakan teknologi informasi dalam mengelola persediaan barangnya. Menurut (Baridwan, 2013), "Persediaan adalah barang yang dimiliki untuk dijual kembali atau digunakan untuk memproduksi barang-barang yang akan dijual".
Pada saat ini teknologi informasi berkembang sangat pesat, sehingga menuntut para pelaku usaha untuk bisa mengikuti kemajuan zaman khususnya dalam dunia teknologi dan informasi. Bukan masalah besar bagi pengusaha atau pelaku dagang dalam melakukan pendataan stok hingga membuat laporan stok harian maupun bulanan barang yang keluar masuk dari gudang (Hidayatulloh, 2014). Terutama perusahaan skala menengah 
ke atas yang sudah terkomputerisasi dalam mengatur ketersediaan barang yang ada di perusahaanya.

Tetapi tidak semua perusahaan sudah memanfaatkan teknologi informasi dalam menjalankan usahanya. Berdasarkan observasi yang penulis lakukan, penulis menemukan masih adanya suatu sistem yang menggunakan cara manual mulai dari pendataan barang masuk, permintaan barang, pengiriman barang, pengembalian barang sampai dengan pembuatan laporan. Hal ini tentunya dapat mengakibatkan penumpukan nota permintaan barang, sulitnya pendataan permintaan barang dari cabang untuk melakukan pengiriman barang, kesalahan barang yang diminta dan yang dikirim, lamanya pencatatan pengembalian barang, kesalahan dalam perhitungan stok barang serta sulitnya untuk mendapatkan laporan pada saat dibutuhkan, seperti laporan permintaan barang, pengiriman barang, serta laporan pengembalian barang.

Dari permasalahan tersebut, penulis mencoba menganalisa kebutuhan-kebutuhan apa saja yang diperlukan suatu perusahaan agar dapat membantu dalam mengelola persediaan barangnya. Sehingga dapat mempermudah dalam proses pencatatan, penyimpanan, pencarian data serta pembuatan laporan. Maka dari itu penulis merancang suatu sistem informasi berbasis web (Abdulloh, 2015) guna mempermudah proses persediaan barang secara online yang diharapkan menjadi salah satu alternatif pemecahan masalah secara efektif dan efisien dalam mengelola sistem persediaan barang.

\section{METODOLOGI PENELITIAN}

RAD adalah suatu pendekatan berorientasi objek terhadap pengembangan sistem yang mencakup suatu metode pengembangan serta perangkat-perangkat lunak (Kendal, 2010). RAD bertujuan mempersingkat waktu yang biasanya diperlukan dalam siklus hidup pengembangan sistem tradisional antara perancangan dan penerapan suatu sistem informasi (Sukamto, R. A., \& Salahudin, 2016). Pada akhirnya, RAD sama-sama berusaha memenuhi syarat-syarat bisnis yang berubah secara cepat. Terdapat tiga fase dalam RAD yang melibatkan penganalisis dan pengguna dalam tahap penilaian, perancangan, dan penerapan. Adapun ketiga fase tersebut adalah requirements planning (perencanaan syaratsyarat), RAD design workshop (workshop desain RAD), dan implementation (implementasi). Sesuai dengan metodologi RAD menurut (Kendal, 2010), berikut ini adalah tahap-tahap pengembangan aplikasi dari tiaptiap fase pengembangan aplikasi.

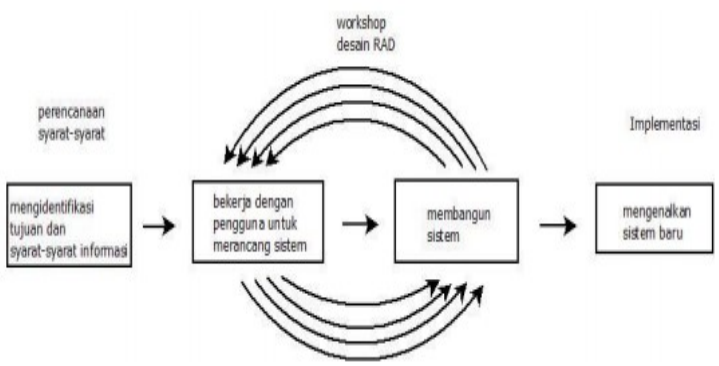

Sumber: (Kendall, 2010)

Gambar 1. Metode RAD (Rapid Application Development)

1. Requirements Planning (Perencanaan Syarat-Syarat)

Dalam fase ini, pengguna dan penganalisis bertemu untuk mengidentifikasikan tujuantujuan aplikasi atau sistem serta untuk mengidentifikasikan syarat-syarat informasi yang ditimbulkan dari tujuan-tujuan tersebut. Orientasi dalam fase ini adalah menyelesaikan masalah-masalah perusahaan. Meskipun teknologi informasi dan sistem bisa mengarahkan sebagian dari sistem yang diajukan, fokusnya akan selalu tetap pada upaya pencapaian tujuan-tujuan perusahaan.

2. RAD Design Workshop (Workshop Desain RAD)

Fase ini adalah fase untuk merancang dan memperbaiki yang bisa digambarkan sebagai workshop. Penganalisis dan dan pemrogram dapat bekerja membangun dan menunjukkan representasi visual desain dan pola kerja kepada pengguna. Workshop desain ini dapat dilakukan selama beberapa hari tergantung dari ukuran aplikasi yang akan dikembangkan. Selama workshop desain RAD, pengguna merespon prototipe yang ada dan penganalisis memperbaiki modulmodul yang dirancang berdasarkan respon pengguna.

3. Instruction (Konstruksi)

Fase Konstruksi merupakan fase eksekusi dalam bentuk pembuatan script program dan merupakan kelanjutan dari fase kedua. Pada fase ini juga menunjukkan platform, hardware, dan software yang digunakan. Setiap desain yang dibuat pada fase sebelumnya, akan ditingkatkan dengan menggunakan perangkat RAD. Setelah fungsi baru tersedia, fungsi baru tersebut ditunjukan kepada pengguna untuk mendapatkan interaksi dan revisi, selanjutnya penganalisis akan melakukan perubahandalam setiap desain aplikasi berdasakan instruksi dari pengguna.

4. Implementation (Implementasi)

Pada fase implementasi ini, penganalisis bekerja dengan para pengguna secara 
intens selama workshop dan merancang aspek-aspek bisnis dan nonteknis perusahaan. Segera setelah aspek-aspek ini disetujui dan sistem-sistem dibangun dan disaring, sistem-sistem baru atau bagian dari sistem diujicoba dan kemudian diperkenalkan kepada organisasi (Kendal, 2010).

Pemaparan konsep yang lebih spesifik lagi dijelaskan oleh (Pressman, 2012) , ia mengatakan bahwa RAD adalah proses model perangkat lunak inkremental yang menekankan siklus pengembangan yang singkat. Model RAD adalah sebuah adaptasi "kecepatan tinggi" dari model waterfall, di mana perkembangan pesat dicapai dengan menggunakan pendekatan konstruksi berbasis komponen. Jika tiap-tiap kebutuhan dan batasan ruang lingkup projek telah diketahui dengan baik, proses RAD memungkinkan tim pengembang untuk menciptakan sebuah "sistem yang berfungsi penuh" dalam jangka waktu yang sangat singkat. Dari penjelasan (Pressman, 2012) ini, satu perhatian khusus mengenai metodologi RAD dapat diketahui, yakni implementasi metode RAD akan berjalan maksimal jika pengembang aplikasi telah merumuskan kebutuhan dan ruang lingkup pengembangan aplikasi dengan baik. Sistem yang memiliki tingkat kedinamisan yang tinggi, ketersediaan waktu dan anggaran biaya pengembangan yang terbatas, untuk kebutuhan informasi terkini secara cepat dan perlunya kedekatan interaksi hubungan yang personal dengan karakteristik penggunaannya lebih tepat menerapkan metode RAD (Kosasi, S., \& Yuliani, 2015).

\section{HASIL DAN PEMBAHASAN}

\section{Analisa Kebutuhan Sistem}

Analisa kebutuhan sistem untuk sistem informasi persediaan barang berbasis web ini adalah:

a. Skenario Kebutuhan Admin

1) Mengelola data user

2) Mengelola data cabang, data supplier data kategori, data barang dan data barang masuk.

3) Mengelola data transaksi permintaan, pengiriman dan pengembalian.

4) Melihat data laporan, mulai dari laporan data user, data cabang, data supplier, data kategori, data barang. Serta seluruh laporan transaksi, mulai dari laporan barang masuk, transaksi permintaan, pengiriman, dan laporan pengembalian barang.

b. Skenario Kebutuhan Staff

1) Menginput data transaksi permintaan.

2) Menginput data transaksi pengembalian barang c. Skenario Kebutuhan Supervisor

1) Menginput dan mengubah data transaksi permintaan

2) Menginput dan mengubah data transaksi pengembalian.

2. Entity Relationship Diagram (ERD)

Berikut merupakan rancangan ERD dalam sistem informasi persediaan barang.

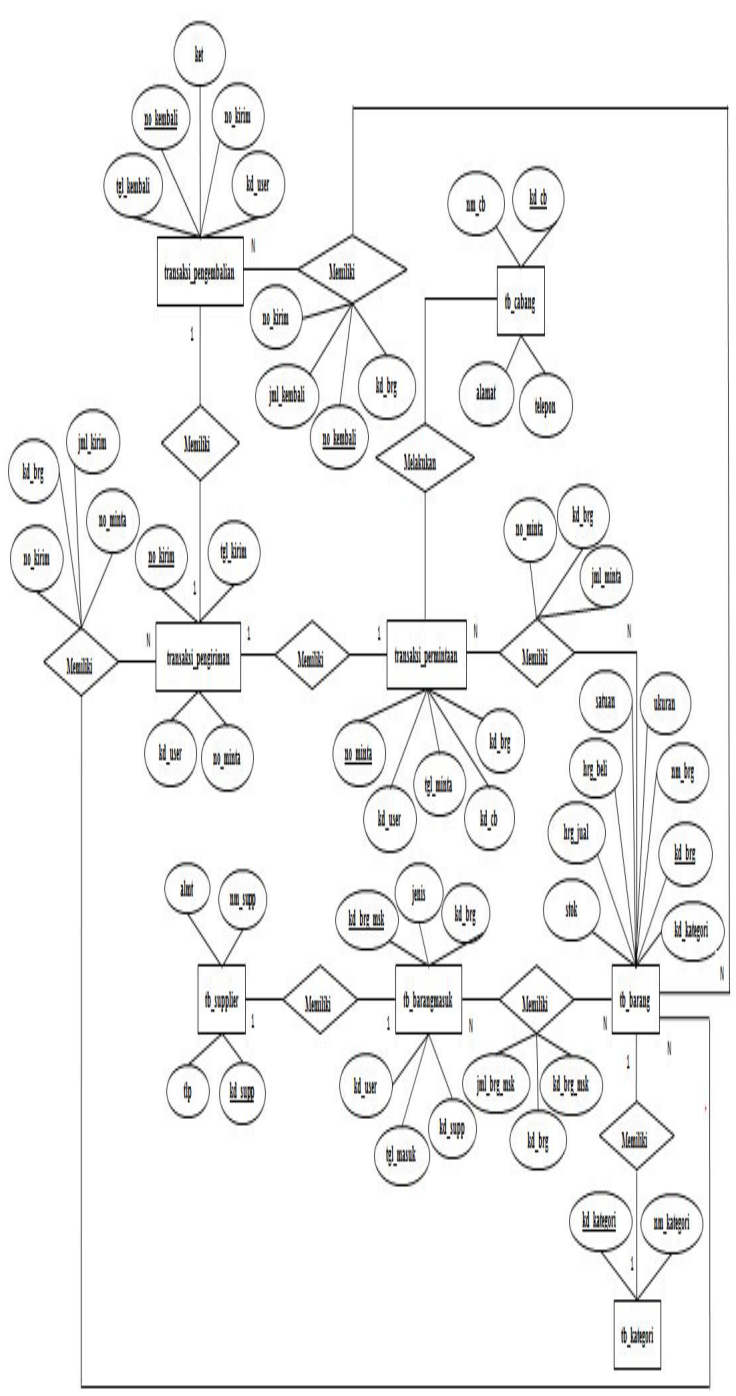

Sumber: Penelitian (2019)

Gambar 2. ERD Sistem Informasi Persediaan Barang

3. Spesifikasi File
a. Spesifikasi File Barang
Nama File
Akronim
Fungsi
: File Barang
tb barang.myd
: Untuk menyimpan data barang
Tipe File : File Master
Organisasi File : Index Sequential File
Akses File : Random
Media : Hard Disk
Panjang Record : 87 Byte
Kunci Field : kd brg
Software : Xampp 
Tabel 1. Spesifikasi File Barang

\begin{tabular}{cccccc}
\hline No & Elemen Data & Akronim & Tipe & Panjang & Ket \\
\hline 1 & Kode Barang & kd_brg & Varchar & 6 & Primary Key \\
2 & Nama Barang & nm_brg & Varchar & 30 & \\
3 & Kode Kategori & kd_kategori & Varchar & 6 & Foreign Key \\
4 & Ukuran & ukuran & Varchar & 15 & \\
5 & Satuan & satuan & Varchar & 15 & \\
7 & Harga & hrg & Double & & \\
8 & Stok & stok & Double & & \\
\hline
\end{tabular}

Sumber : Penelitian (2019)

b. Spesifikasi File Transaksi Permintaan Nama File : File Transaksi

Akronim transaksi_permintaan.myd Fungsi
: Untuk menyimpan data transaksi permintaan
Tipe File : File Transaksi

Organisasi File : Index Sequential File

Akses File : Random

Media : Hard Disk

Panjang Record : 26 Byte

Kunci Field : no_minta

Software : : Xampp

Tabel 2. Spesifikasi File Transaksi Permintaan

\begin{tabular}{|c|c|c|c|c|c|}
\hline No & Elemen Data & Akronim & Tipe & Panjang & Ket \\
\hline 1 & Nomor Permintaan & no_minta & Varchar & 10 & Primary Key \\
\hline 2 & Tanggal Permintaan & tgl_minta & Date & & \\
\hline 3 & Kode Cabang & kd_cb & Varchar & 5 & Foreign Key \\
\hline 4 & Kode Barang & kd_brg & Varchar & 6 & Foreign Key \\
\hline 5 & Kode User & kd_user & Varchar & 5 & Foreign Key \\
\hline
\end{tabular}

Sumber : Penelitian (2019)

4. Spesifikasi Program

a. Struktur Navigasi Halaman Admin

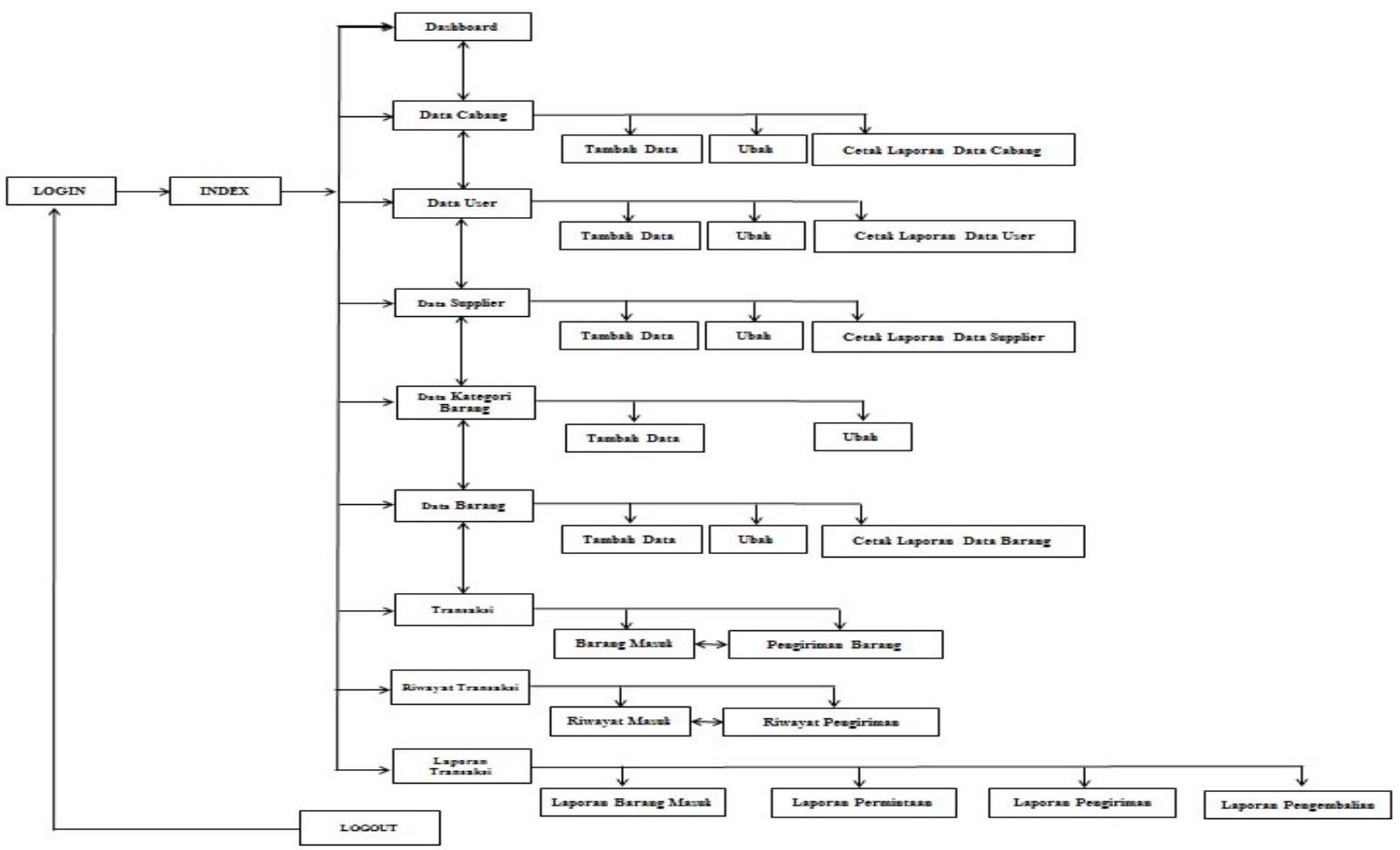

Gambar 3. Struktur Navigasi Halaman Admin 
5. Implementasi Rancangan Antar Muka Implementasi rancangan antar muka pada sistem informasi persediaan barang berbasis web berdasarkan hasil rancangan antar muka.

a. Halaman Login

Admin, Staff dan Supervisor harus melakukan login terlebih dahulu untuk dapat menggunakan modul-modul yang tersedia. Jika login berhasil, maka menumenu yang sesuai dengan kategori admin, staff atau supervisor tersebut akan ditampilkan.

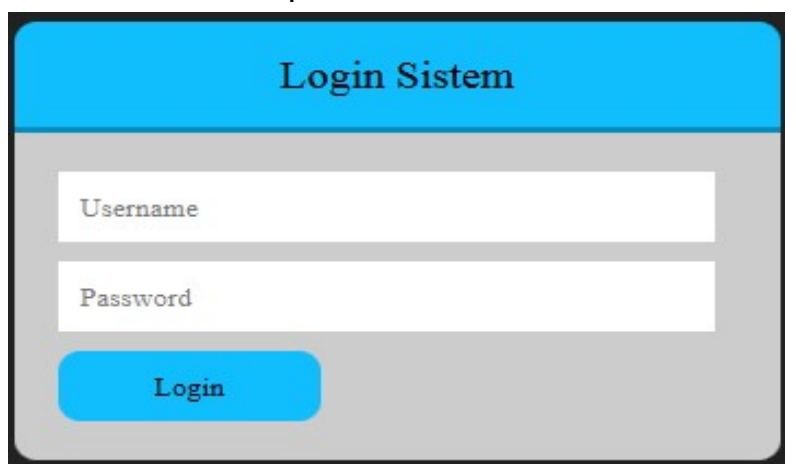

Sumber: Penelitian (2019)

Gambar 4. Halaman Login

b. Halaman Index Admin

Setelah login, admin akan masuk ke dalam halaman index admin, dimana halaman tersebut berisi menu-menu yang dapat di akses oleh admin.

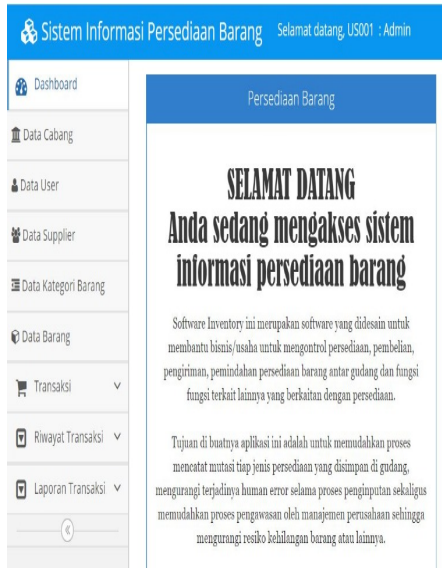

Sistem Informas Persedican Barang B Biktra Rudianto 0202

Sumber: Penelitian (2019)

Gambar 5. Halaman Index Admin

c. Halaman Master Barang

Di halaman ini admin akan melihat datadata tentang barang dan dapat mengedit ataupun menghapus data yang ada di halaman master barang.

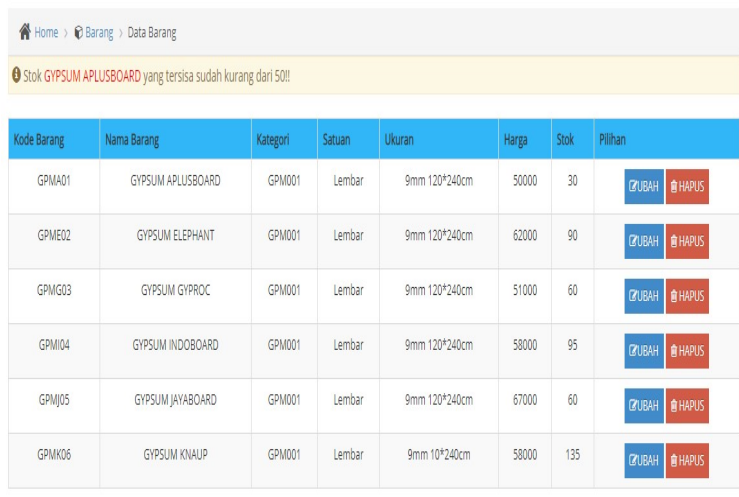

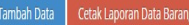

Sumber: Penelitian (2019)

Gambar 6. Halaman Master Barang

d. Halaman Transaksi Barang Masuk

Di halaman ini admin akan melihat data barang masuk dan dapat menginput data barang masuk.

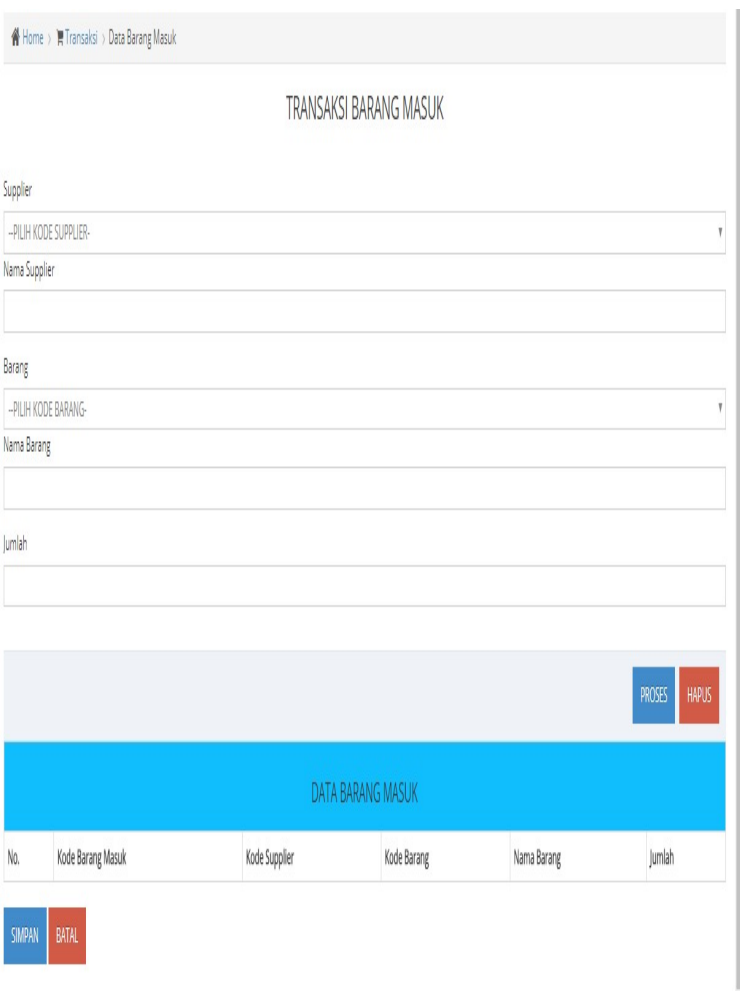

Sumber: Penelitian (2019)

Gambar 7. Halaman Transaksi Barang Masuk

e. Halaman Transaksi Permintaan

Di halaman ini pengguna akan melakukan transaksi permintaan barang. 


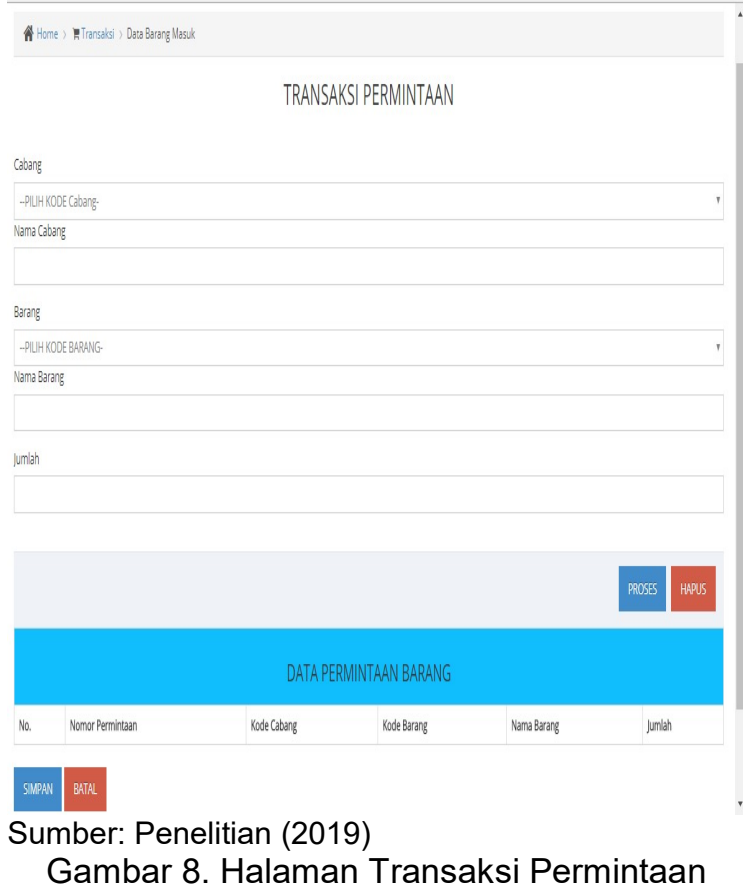

f. Halaman Riwayat Transaksi Masuk Di halaman ini admin dapat melihat riwayat transaksi barang masuk.

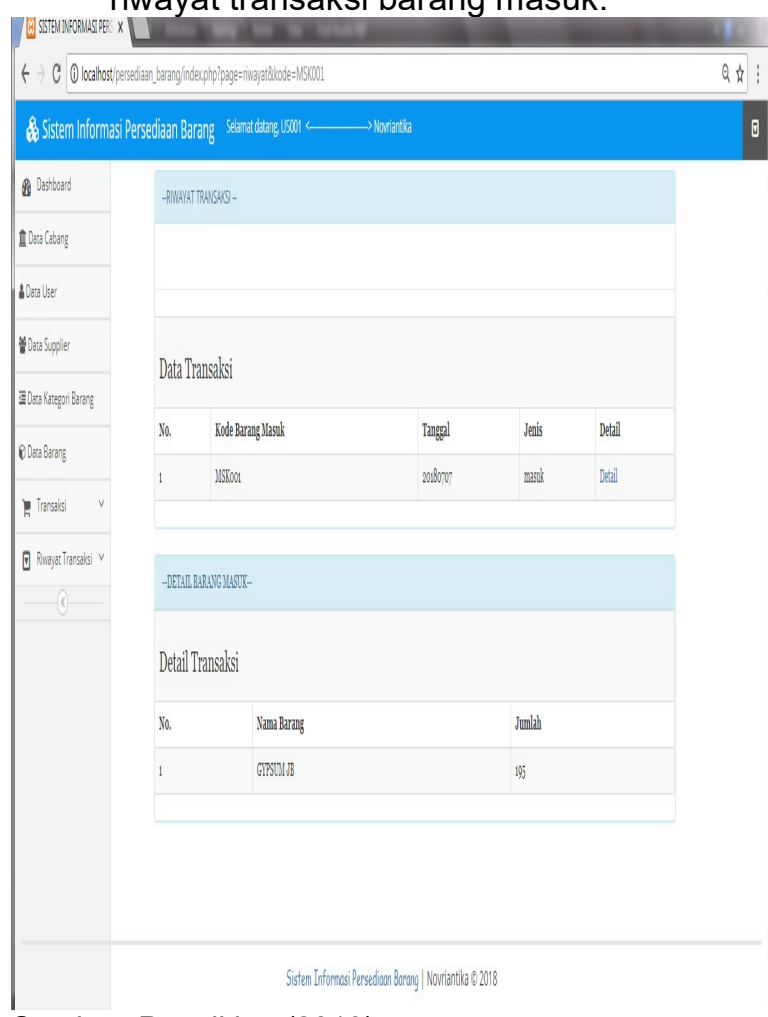

Sumber: Penelitian (2019)

Gambar 9. Halaman Riwayat Transaksi Masuk

6. Pengujian Unit

Pengujian terhadap program sistem informasi persediaan barang yang dibuat menggunakan blackbox testing berfokus terhadap proses masukan dan keluaran (Mustaqbal, 2015).

\section{KESIMPULAN}

Berdasarkan pembahasan yang telah diuraikan oleh Penulis pada penelitian ini, dapat ditarik kesimpulan mengenai perancangan sistem informasi persediaan barang berbasis web, yaitu sebagai berikut:

1. Dengan adanya sistem informasi berbasis web ini, dapat meningkatkan efektifitas dan efesiensi pengolahan data, mulai dari barang masuk, permintaan barang, pengiriman barang, pengembalian barang sampai dengan pembuatan laporan.

2. Dengan adanya sistem informasi berbasis web ini, data yang dibutuhkan dapat disimpan dalam jumlah banyak, dan lebih aman dengan adanya sistem pengamanan yang berupa password dan hak akses.

3. Dapat meminimalisir kesalahan yang mungkin terjadi pada sistem manual.

4. Dengan adanya sistem informasi berbasis web ini, dapat menghindari kerangkapan data dalam proses pengolahan data karena adanya kode yang memiliki karakteristik berbeda antara data satu dengan data yang lainnya.

\section{REFERENSI}

Abdulloh, R. (2015). Web Programming is Easy. Elex Media Komputindo.

Baridwan, Z. (2013). Sistem Informasi Akuntansi (Edisi Kedu). BPFE.

Hidayatulloh, P. D. (2014). Pemrograman Web. Informatika Bandung.

Kendal, K. D. (2010). Analisis dan Perancangan Sistem. Prehallindo.

Kosasi, S., \& Yuliani, I. D. A. E. (2015). Penerapan Rapid Application Development Pada Sistem Penjualan Sepeda Online. Simetris: Jurnal Teknik Mesin, Elektro Dan IImu Komputer, 6, 2736.

http://jurnal.umk.ac.id/index.php/simet/arti $\% 0$ Acle/view/234/231

Mustaqbal, M. S. (2015). Pengujian Aplikasi Menggunakan Black Box Testing Boundary Value Analysis (Studi Kasus: Aplikasi Prediksi Kelulusan SNMPTN). Jurnal IImiah Teknologi Informasi Terapan, 31-36.

Pressman, R. S. (2012). Rekayasa Perangkat Lunak. In Buku 1 Pendekatan Praktisi edisi 7 (Edisi 7). Andi.

Priyadi, Y. (2014). Kolaborasi SQL \& ERD Dalam Implementasi Database (Maya, Ed). Andi Offset.

Sukamto, R. A., \& Salahudin, M. (2016). Rekayasa Perangkat Lunak Terstruktur dan Berorientasi Objek. Informatika. 